\title{
A New Perspective for Osteosarcoma Therapy: Proteasome Inhibition by MLN9708/2238 Successfully Induces Apoptosis and Cell Cycle Arrest and Attenuates the Invasion Ability of Osteosarcoma Cells in Vitro
}

\author{
Renhao Liu Chunjiang Fu Jiabing Sun Xvming Wang Shuo Geng Xiaoyu Wang \\ Jilong Zou Chenglin Yang Zhenggang Bi
}

Department of Orthopaedic Surgery, the First Affiliated Hospital of Harbin Medical University, Harbin, China

\section{Key Words}

Osteosarcoma (OS) • Protein homeostasis • Proteasome • Proteasome inhibitor $\bullet$ MLN9708/2238

- Mitochondria $\cdot$ Apoptosis $\cdot$ Cell cycle arrest $•$ Cell invasion

\begin{abstract}
Background: The proteasome exists in all eukaryotic cells and provides the main route of intracellular proteins degradation involved in cell growth and apoptosis. Proteasome inhibition could block protein degradation pathways and disturb regulatory networks, possibly leading to profound effects on cell growth, particularly in cancer cells. A proteasome inhibitor with an appropriate toxicity index for malignant cells rather than normal cells would be an attractive anticancer therapy. Methods: The human osteosarcoma (OS) cell lines MG-63 and Saos-2 and normal osteoblast cells were used to study the antitumour activity of the proteasome inhibitor MLN9708/2238. Results: MLN2238 inhibited cell growth, induced cell cycle arrest and apoptosis, and attenuated the invasion abilities of MG-63 and Saos-2 cells, with little cytotoxicity to normal cells. In addition, MLN2238 promoted antitumour mechanisms including the accumulation of E2F1, P53, P21 and other negative G2/M checkpoint proteins; up-regulated the relative expression ratio of BAX/BCL-2, APAF-1 and pro-apoptotic proteins of the $\mathrm{BCL}-2$ family; triggered mitochondrial outer membrane permeabilization (MOMP); down-regulated BCL-2 and XIAP; activated caspase3/8/9; and suppressed MMP2/9 expression and secretion levels. Conclusions: The proteasome may be a novel biochemical target for OS treatment in vitro. Our study provides a promising mechanistic framework for MLN9708/2238 in OS treatment, supporting its clinical development.




\section{Introduction}

Protein homeostasis plays an important role throughout the life of cells. To maintain normal cell metabolisms, both activation/inactivation of critical proteins at appropriate times and sites and the timely removal of unfolded, misfolded or errant proteins are highly important. Protein degradation is a complex process and occurs mainly through two routes: lysosomes and proteasomes. Lysosomes degrade extracellular and transmembrane proteins, and proteasomes are primarily involved in degrading intracellular proteins [1]. The proteasome is a multi-catalytic complex that exists in all eukaryotic cells and functions through the ubiquitin-proteasome system (UPS). During protein degradation, the targeted proteins are first marked by ubiquitin, and the ubiquitinated proteins are recognized by the proteasome and degraded to peptides and free ubiquitin [2]. Substrates of the UPS include damaged or misfolded proteins and various regulatory proteins that have multiple functions in physiological and pathophysiological cellular processes, such as cell growth, apoptosis and neoplastic growth [3]. Malignant cells, which are characterized by rapid proliferation and an aberrant response to apoptosis, are assumed to require more proteasomes than normal cells for protein homeostasis to sustain their efficient biological activities [4-6].

In view of aberrant proteasome expression, proteasome inhibition has emerged as an attractive oncotherapy method. Empirical findings have indicated that tumour cells are more sensitive to proteasome inhibition than normal cells $[7,8]$. For example, proteasome inhibitors induce apoptosis significantly in human chronic lymphocytic leukaemia [4], oral squamous cell carcinoma [9], human multiple myeloma [7] and human PC-3 prostate tumour cells [10] compared with their corresponding non-cancerous cells. The inhibition of proteasomes insulates their substrates from degradation, and the accumulation of these substrates can jeopardize cell function and even survival, particularly in malignant cells, and disturb the abnormal vigorous growth regulatory framework, ultimately inducing apoptosis $[3,11,12]$. Although diverse mechanisms have been reported, much remains to be learned about the exact sequence of events and how these events are specific to a certain inhibitor or tumour type.

Osteosarcoma (OS), the most common primary malignancy of the bone, is prevalent mostly in adolescents and children and is notorious for distal metastasis. Almost $80 \%$ of the patients will develop or already have radio-graphically undetectable micro-metastases. Unfortunately once a metastasis has been detected, the disease is likely to relapse. With surgical resection and chemo- and radio-therapy for non-metastatic patients, 5-year survival is 60\%-70\%; however for patients who present with metastatic disease or whose tumour recurs, outcomes are far worse with $<30 \%$ and $<20 \%$ survival respectively [13-15]. Due to these poor outcomes and increasing drug resistance and toxic side effects of chemotherapy in the treatment of OS, more efficient therapeutic approaches are urgently needed.

MLN9708 is an investigational small-molecule proteasome inhibitor that is currently being evaluated in multiple phase I clinical studies. As an orally bioavailable agent, MLN9708 is a citrate ester that is immediately hydrolysed to its biologically active form MLN2238, upon exposure to aqueous solutions or plasma [8]. MLN2238 has an improved pharmacokinetic and pharmacodynamic profile and a shorter proteasome dissociation half-life than previous proteasome inhibitors, thus, MLN2238 exhibits greater distribution and greater effects in tumour tissue than in the blood $[8,16]$. Few systematic studies of proteasome inhibitor treatment for OS have been reported, particularly treatment involving MLN9708/2238. In this study, we used two OS cell lines, MG-63 and Saos-2 (deficient in $\mathrm{P} 53$ and $\mathrm{Rb}$ ), to investigate the possible molecular mechanisms involved in the antitumour effects of MLN2238 in vitro. We determined that MLN2238 functioned well in the two cell lines with respect to its antitumour effects, including growth inhibition, cell cycle arrest, and apoptosis. More importantly, MLN2238 attenuated OS cell invasion abilities with decreased expression and exocytosis of MMP2/9. These findings suggest that the proteasome inhibitor MLN9708/2238 may be an attractive anticancer agent for OS. 


\section{Cellular Physiology Cell Physiol Biochem 2017;41:451-465

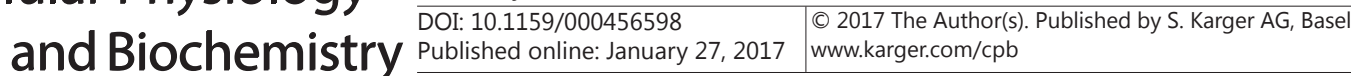

Liu et al.: Proteasome Inhibition in Osteosarcoma Therapy

\section{Materials and Methods}

\section{Cell culture and treatment}

The cell lines MG-63, Saos-2 and hFOB 1.19 were purchased from the Type Culture Collection of the Chinese Academy of Sciences, Shanghai Institute of Cell Biology, China. The cells were cultured in DMEM (high glucose) supplemented with $10 \% \mathrm{FBS}, 100$ units $/ \mathrm{ml}$ penicillin and $100 \mathrm{mg} / \mathrm{ml}$ streptomycin at $37^{\circ} \mathrm{C}$ in a humidified atmosphere of $95 \%$ air and $5 \% \mathrm{CO}_{2}$; for hFOB 1.19 cell culture, $0.3 \mathrm{mg} / \mathrm{ml} \mathrm{G418}$ was also added, and the cells were cultured at $33.5^{\circ} \mathrm{C}$. The cells treated with MLN2238 and DMSO (vehicle) in this study were all first 'starved' for $12 \mathrm{~h}$ which means after cell adherence, complete medium was replaced with basal medium, followed by treatment with MLN2238 and DMSO dissolved in fresh basal medium. Additionally, the final DMSO concentration of MLN2238 $(0-3.20 \mu \mathrm{M})$ was much less than $0.1 \%$, because the concentration of the stock solution of MLN2238 was $10 \mathrm{mM}$.

\section{Reagents and antibodies}

MLN9708 was purchased from Millennium Pharmaceuticals, Inc. (Cambridge, MA, USA). Antibodies used were Caspase3/8/9 (9662/9746/9502), PARP (9542), MMP2/9 (4022/3852), APAF-1 (5088), BCL-2 (2872), Rb (9309), BID (2002) and COX IV (4844; all from Cell Signalling Technology; Beverly, MA, USA); P53 (ab1101), P21 (ab109199), BAX (ab32503), BAD (ab32445), p-BAD (Ser136, ab28824), P-CHK1 (Ser345, ab58567), Cytc (ab13575), Smac (ab32023) and OMI (ab75982; all from Abcam; Cambridge, UK); CDK1 (A0220) and p-CDK1 (Tyr15, AP0016; both from Abclonal; Woburn, MA, USA); WEE1 (sc-5285), E2F1 (sc137059), XIAP (sc-55550), NOXA (sc-56169) and PUMA (sc-374223; all from Santa Cruz Biotechnology; Eugene, OR, USA); Actin (PR-0255; ZSGB-BIO, Beijing, China); Tubulin (AT819; Beyotime, China). DMSO was obtained from Sigma-Aldrich (St. Louis, MO, USA) and MTT was obtained from Amresco (Solon, OH, USA).

\section{Cell proliferation assays}

Cell viability was assessed using the MTT assay. Cells were trypsinized and seeded in 96-well plate at 5000 cells per well. Cells were treated with MLN2238 or DMSO in basal medium at the indicated doses and times, as shown in the Figures and/or corresponding Figure legends. Cell viability was determined relative to control cells treated with vehicle alone.

\section{Flow cytometric analysis}

For apoptosis assays, the cells were treated with MLN2238 and DMSO at the indicated doses for $24 \mathrm{~h}$. The cells were collected and washed three times with cold PBS, and then resuspended in binding buffer. Next, the cells were stained with Annexin V-FITC/PI (BD Pharmingen ${ }^{\mathrm{TM}}$ ) in the dark at room temperature for $15 \mathrm{~min}$, followed by analyzed using a fluorescence-activated cell-sorting (FACS) flow cytometer (BD Pharmingen ${ }^{\mathrm{TM}}$, USA). Apoptotic cells were evaluated based on PI and Annexin V positive cells. For cell cycle analysis, cells were harvested and washed with buffer solution three times at room temperature. Next, the supernatant was removed, and the cells were incubated with solution A and B sequentially for $10 \mathrm{~min}$ at room temperature, followed by incubation with solution C (PI) for $10 \mathrm{~min}$ in the dark at $4^{\circ} \mathrm{C}$ and analysed using a flow cytometer (BD Pharminge ${ }^{\mathrm{TM}}$, USA). The apoptosis and cell cycle data were analysed using FlowJo V10 and ModiFit LT 4.1 software, respectively.

\section{Western blot analysis}

The cells were lysed with RIPA buffer containing $1 \%$ protease inhibitor, and the total cell lysates were sonicated for $15 \mathrm{~s}$. The supernatants were collected after centrifugation at $13,500 \mathrm{~g}$ for $15 \mathrm{~min}$ at $4^{\circ} \mathrm{C}$, and then the protein concentrations were determined with a BCA Protein Assay Kit (Beyotime, China). The proteins were separated by SDS-PAGE and transferred to nitrocellulose membranes. After blocking with $5 \%$ non-fat milk for $2 \mathrm{~h}$ at room temperature, the membranes were incubated with the primary antibodies described above over night at $4^{\circ} \mathrm{C}$. Next, the appropriate secondary antibody conjugated with horseradish peroxidase (goat anti-rabbit or goat anti-mouse antibodies; ZSGB-BIO, Beijing, China) and enhanced chemiluminescence substrate (Thermo, Biotechnology, Germany) were used to visualize the protein bands. The films were scanned using the Epson Perfection V300 Scanner (EPSON), and the intensity of each band was quantified by densitometry analysis using Image-Pro Plus 4.5 software. 


\section{Cellular Physiology Cell Physiol Biochem 2017;41:451-465 \begin{tabular}{l|l|l} 
DOI: 10.1159/000456598 & $\begin{array}{l}\text { O 2017 The Author(s). Published by S. Karger AG, Basel } \\
\text { www.karger.com/cpb }\end{array}$
\end{tabular}}

Liu et al.: Proteasome Inhibition in Osteosarcoma Therapy

\section{Subcellular fractionation and western blot analyses}

Subcellular fractions were obtained as described by Liu et al and Wu et al [17, 18]. Mitochondrial and cytoplasmic proteins were obtained using a mitochondrial isolation kit for cultured cells (Abcam, ab110170). Briefly, according to the manufacturer's protocol, the cells treated with MLN2238 and DMSO at the indicated time points and doses, were collected and centrifuged at $1000 \mathrm{~g}$ for $5 \mathrm{~min}$. cells were resuspended in reagent $\mathrm{A}$ at $5 \mathrm{mg} / \mathrm{ml}$ and incubated on ice for $10 \mathrm{~min}$. Cell suspension were then homogenized on ice and centrifuged at $1000 \mathrm{~g}$ for $10 \mathrm{~min}$ at $4^{\circ} \mathrm{C}$ to remove nuclei and unbroken cells. The supernatant (supernatant 1) was retained. The pellet was resuspended in reagent $B$, homogenized and centrifuged again as above, and the supernatant (supernatant 2) was retained. Supernatants 1 and 2 were combined, mixed thoroughly, and centrifuged at $12,000 \mathrm{~g}$ for $15 \mathrm{~min}$ at $4^{\circ} \mathrm{C}$ to isolate the cytosolic (supernatant) and mitochondrial (deposition) fractions. The cytosolic and mitochondrial fractions were dissolved in lysis buffer and proteins were subjected to western blotting as described above.

\section{In vitro invasion assays}

Invasion analysis was performed using the BD BioCoat Fluoroblok Tumor Invasion System (BD Biosciences), which characterized by a light-tight polyethylene terephthalate membrane with $8 \mu \mathrm{m}$ pores and coated with reconstituted basement membrane gel. Invasion assays were performed according to the manufacturer's instructions. Briefly, $1.0 \times 10^{5}$ cells were seeded into the upper chamber with $500 \mu \mathrm{L}$ serumfree medium, and then $750 \mu \mathrm{L} 20 \%$ FBS-enriched medium was added to the basal chamber as a chemoattractant for cell invasion. After incubation for 12h, cells were treated with MLN2238 and DMSO (vehicle) for $24 \mathrm{~h}$. Cells that invaded through the Matrigel were labeled with $4 \mu \mathrm{g} / \mathrm{mL}$ Calcein AM (BD Biosciences) in $\mathrm{HBSS}$ and Incubated for $1 \mathrm{~h}$ at $37^{\circ} \mathrm{C}$ in $5 \% \mathrm{CO}_{2}$. As a bottom-reading fluorescent plate reader device is not available in our laboratory, the results were evaluated by counting the number of cells that adhered to the lower surface of the membrane under an inverted fluorescence microscope (IX73, Olympus). The number of invaded cells was counted in six random fields.

\section{Data analysis}

Data analysis was performed using GraphPad Prism software (version 5) and the results were presented as mean \pm SD. Significance was determined using Student's t test or one-way ANOVA, followed by the Holm-Sidak post-test. $\mathrm{P}<0.05$ was considered significant.

\section{Results}

MLN2238 treatment inhibits growth and promotes apoptosis of human osteosarcoma cells

We assessed the effects of various doses of MLN2238 on the viability of OS cells (MG-63 and Saos-2) using the MTT assay. As shown in Fig. 1A, MLN2238 inhibited the cell growth of both cell lines effectively in a time- and dose-dependent manner $(\mathrm{n}=5, \mathrm{P}<0.05)$. By contrast, MLN2238 exhibited much lower cytotoxicity against normal osteoblast cells (hFOB1.19), even when administered at the maximum dose of $3.20 \mu \mathrm{M}$ for up to $48 \mathrm{~h}$, suggesting a favourable therapeutic index $(\mathrm{n}=5, \mathrm{P}<0.05)$. The $50 \%$ growth inhibition (IC50; $\mathrm{n}=3, \mathrm{P}<$ 0.05 ) values of MG-63 and Saos-2 with the specific treatment times are shown in Fig. 1B. In addition, the growth inhibition caused by MLN2238 is partially attributable to apoptosis, as evidenced by the significant increase in the Annexin $\mathrm{V}^{+} / \mathrm{PI}^{-}$and Annexin $\mathrm{V}^{+} / \mathrm{PI}^{+}$apoptotic cell populations of MG-63 and Saos-2 cells (Fig.1C; $\mathrm{n}=3, \mathrm{P}<0.05$ ).

\section{MLN2238 treatment disturbs cell cycle progression}

To further detect growth inhibition by MLN2238, cell cycle progression was investigated by propidium iodide staining and FACS analysis. MG-63 and Saos-2 cells were treated with MLN2238 at the indicated doses for $6 \mathrm{~h}, 12 \mathrm{~h}$ and $24 \mathrm{~h}$ separately. The MG-63 and Saos- 2 cells exhibited progressive accumulation in $\mathrm{S}$ and $\mathrm{G} 2 / \mathrm{M}$ phases corresponding to a decrease in G1, indicating an S and G2/M cell cycle arrest. Notably, cell cycle arrest did not initiate until the $12 \mathrm{~h}$ time point and progressed dramatically up to $24 \mathrm{~h}$ (Fig. 2A; n=3). Moreover, as 
A

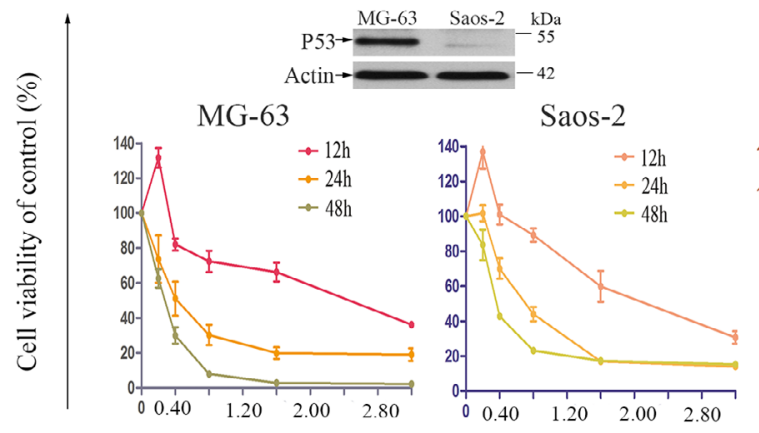

hFOB1.19

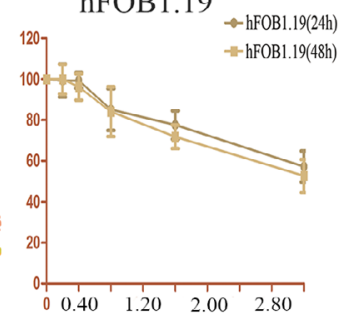

B

MLN2238(uM)

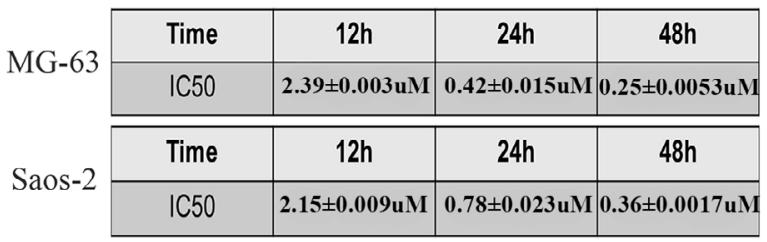

C

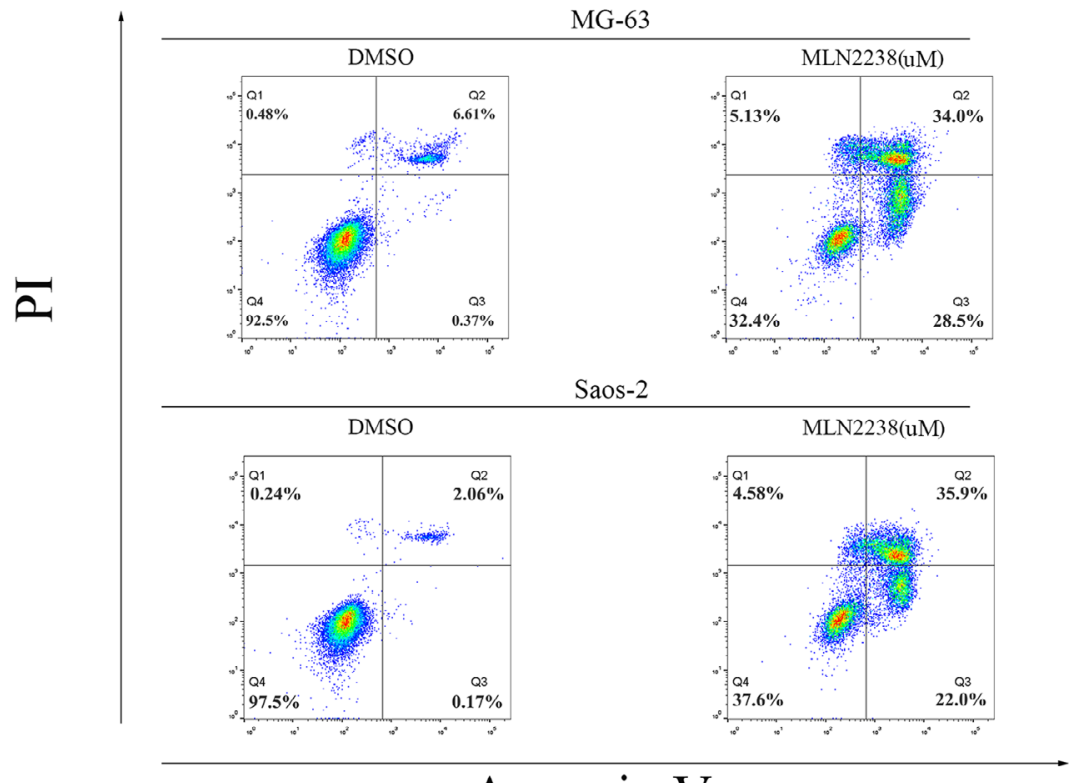

Annexin V

Fig. 1. MLN2238 inhibits growth and induces apoptosis in MG-63 and Saos-2 cells. A, MG-63 and Saos-2 cells were treated with MLN2238 at doses from $0.20 \mu \mathrm{M}$ to $3.20 \mu \mathrm{M}$ for $12 \mathrm{~h}$, $24 \mathrm{~h}$ or $48 \mathrm{~h}$, and cell viability was assessed by MTT assays; hFOB1.19 cells were treated at the same doses as OS cells for $24 \mathrm{~h}$ and $48 \mathrm{~h}$. The P53 null status of the Saos-2 cell line was confirmed by western blotting. The data are presented as means \pm SD $(\mathrm{n}=5 ; \mathrm{P}<0.05$ for all cell lines). B, The IC50 values are shown in the text with the corresponding treatment times for both cell lines; The data are presented as the means $\pm \mathrm{SD}$ ( $\mathrm{n}=3 ; \mathrm{P}<0.05$ for both cell lines). C, MG63 and Saos- 2 cells were treated with MLN2238 at the IC50 dose for each cell line in the 24h treatment for $24 \mathrm{~h}$ and apoptosis was analysed using the Annexin V/PI staining assay. The results are representative of three independent experiments.

shown in Fig. 2B, at the $12 \mathrm{~h}$ time point MG-63 cells exhibited a marked transition from $\mathrm{S}$ to G2/M phase, whereas Saos-2 cells underwent a different G1-S transition ( $n=3)$. To further KARGER 


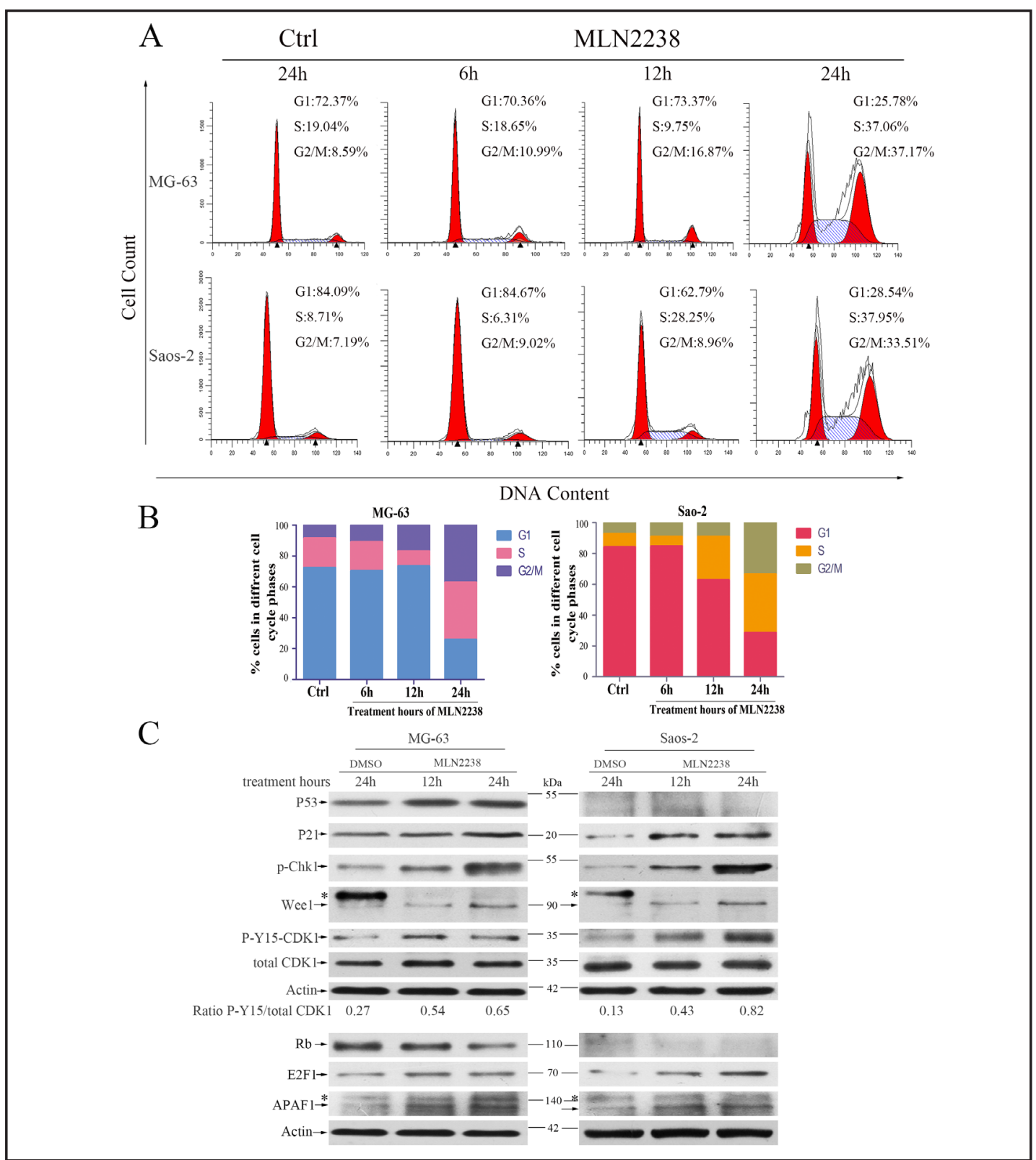

Fig. 2. MLN2238 induces cell cycle arrest in MG-63 and Saos-2 cells. MG-63 and Saos-2 cells were treated with their IC50 doses in the $24 \mathrm{~h}$ treatment $(0.40 \mu \mathrm{M}$ and $0.80 \mu \mathrm{M})$, for $6 \mathrm{~h}, 12 \mathrm{~h}$ and $24 \mathrm{~h}$. Cell cycle status was analysed by FACS after PI staining. A and B, The cell cycle distribution of both cell lines did not show significant changes after $6 \mathrm{~h}$ of treatment; after $12 \mathrm{~h}$ of treatment, MG-63 cells showed a nearly two-fold increase in the S-G2/M transition, whereas Saos-2 cells exhibited a difference in the G1-S transition; at 24h, both cell lines were arrested in $\mathrm{S}$ and G2/M phases compared with the control groups. The results are representative of three independent experiments. C, MG-63 and Saso-2 cells were treated with MLN2238 at the above doses for $12 \mathrm{~h}$ and $24 \mathrm{~h}$ and were then harvested; whole-cell lysates were subjected to western blot analysis to detect the protein levels of P53, p21, p-Chk1 (Ser345), WEE1, CDK1 (total), p-Y15-CDK1, Rb, E2F1 and APAF1. *: nonspecific band. The blots shown in the figure are representative of 3 independent experiments. Actin was monitored to control for equal loading.

understand the mechanism of cell cycle arrest caused by MLN2238, cell cycle regulatory molecules were analysed at $12 \mathrm{~h}$ and $24 \mathrm{~h}$ (Fig. 2C). In accordance with the above results, a time-dependent increases in P21, p-Chk1 (p-Ser345), WEE1 and p-CDK1 (p-Y15) protein 


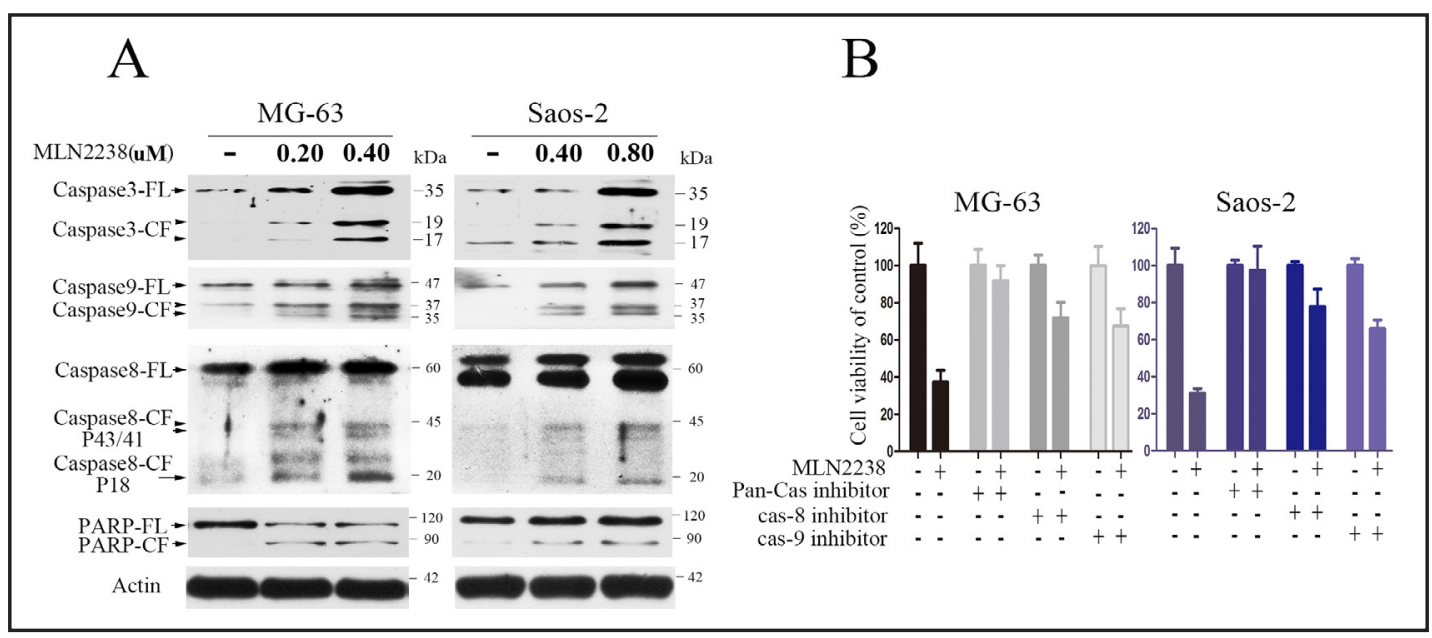

Fig. 3. MLN2238 induces the activation of caspases. A, MG-63 and Saos- 2 cells were treated with MLN2238 for $24 \mathrm{~h}$ at the indicated doses. The cells were harvested, and whole-cell lysates were subjected to western blot analysis with caspase3, caspase9, caspase8 and PARP antibodies. FL: full length; CF: cleaved fragment. Actin was monitored to control for equal loading. The results are representative of three independent experiments. B, MG-63 and Saos-2 cells were treated at the IC50 doses in the $24 \mathrm{~h}$ treatment for $24 \mathrm{~h}$. Before the addition of MLN2238, the cells were pre-treated with biochemical inhibitors of caspase-8 (IETD-FMK), caspase-9 (LEHD-FMK), or pan-caspase (Z-VAD-FMK) for $1 \mathrm{~h}$, and then MLN2238 was added to the cultures for an additional $24 \mathrm{~h}$. Next, cell viability was evaluated by the MTT assay. The data presented as means \pm $\mathrm{SD}(\mathrm{n}=3 ; \mathrm{P}<0.05)$.

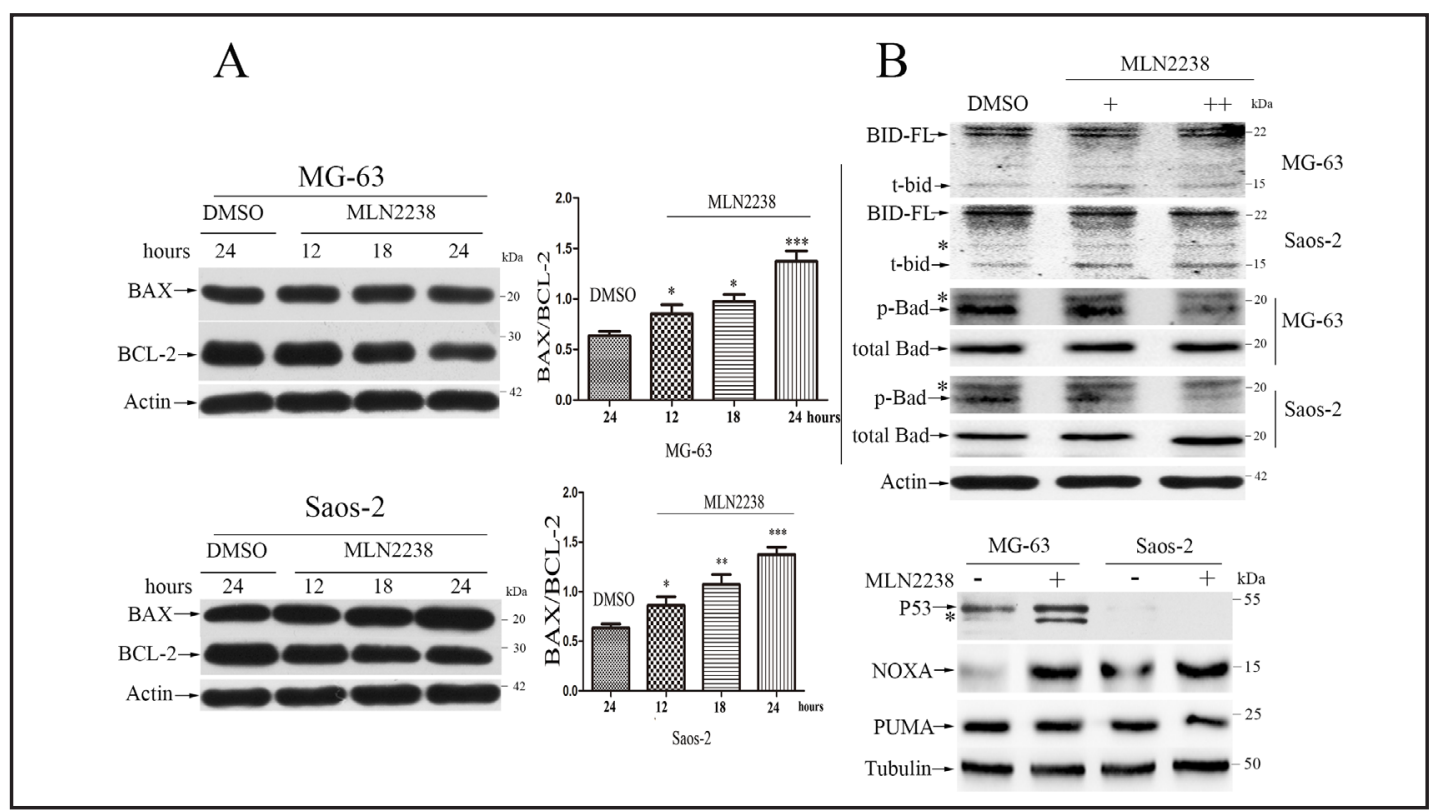

Fig. 4. MLN2238 treatment increases the levels of pro-apoptotic proteins and down regulates the anti-apoptotic proteins that control MOMP. A, MG-63 and Saos-2 cells were treated with MLN2238 at the IC50 doses in the $24 \mathrm{~h}$ treatment, for the indicated times and then harvested. Whole-cell lysates were subjected to western blot analysis with BAX and BCL-2 antibodies. The data for the band intensity ratio of BAX/BCL-2 presented as means $\pm \mathrm{SD}\left(\mathrm{n}=3 ;{ }^{*} \mathrm{P}<0.05 ;{ }^{*} \mathrm{P}<0.01 ;{ }^{* * *} \mathrm{P}<0.001\right)$. Actin was monitored to control for equal loading. $\mathrm{B}$, MG-63 and Saos- 2 cells were treated for $24 \mathrm{~h}$ at the indicated doses (+: $0.40 \mu \mathrm{M}$ for MG-63; +: $0.80 \mu \mathrm{M}$ for Saos-2). The whole-cell lysates were subjected to western blot analysis to detect BID, p-BAD, BAD (total), P53, NOXA and PUMA. *: nonspecific band. Tubulin was monitored to control for equal loading. The blots shown in the figure are representative of 3 independent experiments.

\section{KARGER}


Fig. 5. MLN2238 treatment induces the release of Cytc, Smac, OMI from mitochondria and decreases the protein levels of XIAP. A, MG-63 and Saos-2 cells were treated with MLN2238 at the IC50 doses in the $24 \mathrm{~h}$ treatment for the indicated times. Mitochondria (Mito) and cytoplasm (Cyto) fractions were obtained as described in methods, and then subjected to western blot analysis with Cytc, Smac and OMI antibodies; and additionally, the Cyto fractions were subjected to western blot to detect the protein levels of XIAP. Actin was monitored for cytoplasm fractions to control for equal loading and COX IV for mitochondria fractions was used. B, MG-63 and Saos-2 cells were treated as in $\mathrm{A}$ and then harvested. Whole-cell lysates were subjected to western blot analysis with PARP antibody. FL: full length; CF: cleaved fragment. Actin was monitored to control for equal loading. Blots shown in the figure are representative of 3 independent experiments.

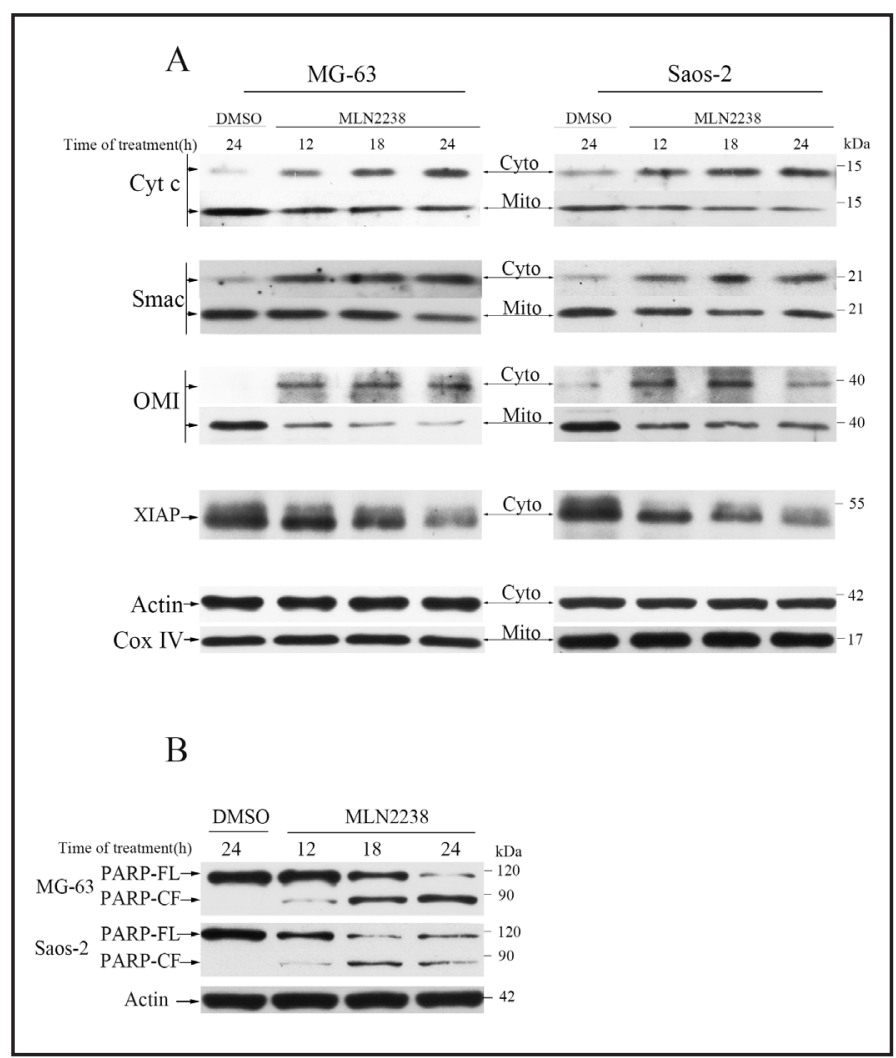

levels were observed in both cell lines and the ratio of p-Y15-CDK1/CDK1 (total) presented an increased tendency over time $(\mathrm{n}=3, \mathrm{P}<0.05)$. Moreover, MLN2238 up regulated the protein levels of P53 (MG-63 only), E2F1 and apoptotic protease activating factor 1 (APAF-1) significantly, and Rb levels decreased slightly over time in MG-63 cells but not in Saos- 2 which are $\mathrm{Rb}$ null (Fig. 2C; $\mathrm{n}=3, \mathrm{P}<0.05$ ). Together, these results suggeste that the dysregulation of cell cycle regulators by MLN2238 might contribute to the observed cell cycle arrest.

\section{MLN 2238 treatment induces caspase activation}

Next, we determined the effects of MLN2238 on the activation of caspases in MG-63 and Saos- 2 cells. Treatment with MLN2238 at the indicated concentrations for $24 \mathrm{~h}$ caused a significant dose-dependent increase in the proteolytic cleavage of caspase-3, caspase-8, caspase- 9 and PARP, as indicated by the appearance of cleaved forms of these proteins (Fig. $3 \mathrm{~A} ; \mathrm{n}=3, \mathrm{P}<0.05$ ). Caspase inhibitors were used to further detect the effects of MLN2238. As shown in Fig. 3B, incubation with the pan-caspase inhibitor (Z-VAD-FMK) notably abrogated the apoptosis induced by MLN2238 in both cell lines, whereas the inhibitors of caspase8 (IETD-FMK) and caspase9 (LEHD-FMK) equally but not completely attenuated the cytotoxicity of MLN2238 ( $\mathrm{n}=3, \mathrm{P}<0.05)$. These results suggest that MLN2238 induces apoptosis mainly through the caspases pathway and requires the activation of both caspase 8 and caspase9.

Effects of MLN2238 treatment on mitochondrial outer membrane permeabilization (MOMP)

To further characterize the mechanism of apoptosis induced by MLN2238 treatment, we determined the expression of BCL-2 family proteins that control mitochondrial outer membrane permeabilization (MOMP). First, we performed a time-course analysis to examine the expression levels of BAX and BCL-2, which are two key regulators of MOMP. As shown in Fig. 4A, over time, the levels of BAX increased moderately in both cell lines, whereas the 
Fig. 6. MLN2238 inhibits the invasion ability of MG-63 and Saos2 cells and decreases both the expression and secretion levels of MMP2/9. A, MG-63 and Saos2 cells $\left(1.0 \times 10^{5}\right.$ cells $)$ were seeded onto the upper chamber in the absence of serum for $12 \mathrm{~h}$, the basal chamber added with $20 \%$ FBS-enriched media and then cells were treated with the indicated doses of MLN2238 for another 24h. Cells were then subjected to invasion assay. MLN2238 significantly decreased MG-63 and Saos- 2 cells invasion ability in a dose dependent manner relative to vehicle-treated control cells. Data presented are means \pm SD $\left(\mathrm{n}=3 ;{ }^{* *} \mathrm{P}<0.01 ; * * * \mathrm{P}<0.001\right)$. B, MG-63 and Saos-2 cells were treated at the indicated doses for $24 \mathrm{~h}$. Culture medium and whole-cell lysates were subjected to western analysis with MMP2/9 antibodies. FL: full length; CF: cleaved fragment; FL\&CF: full length and cleaved fragment. Actin was monitored to control for equal loading. Blots shown in the figure are representative of 3 independent experiments.

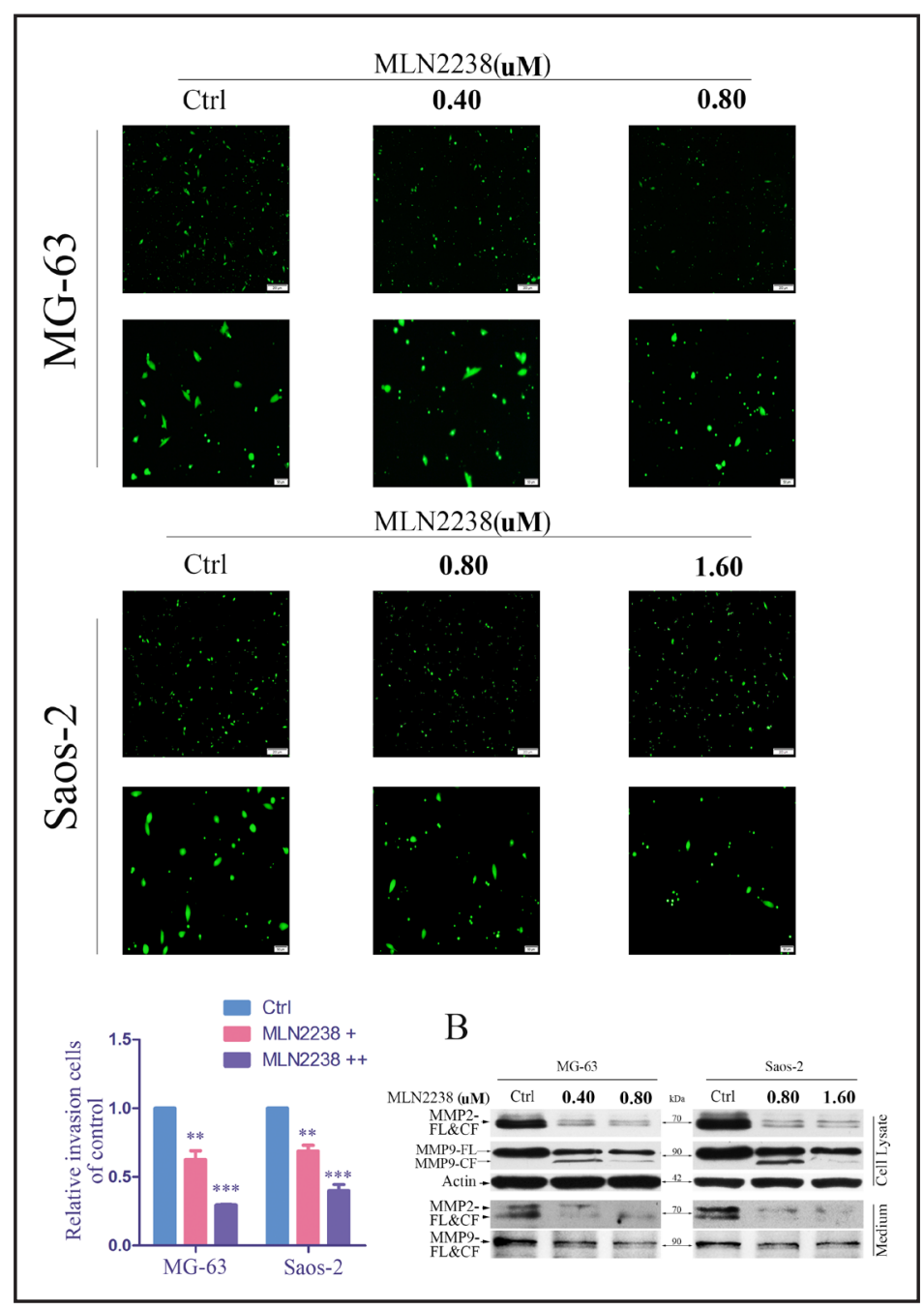

levels of BCL-2 decreased markedly. In the presence of antagonistic factors of the regulation of MOMP, the relative expression ratio of BAX/BCL-2 increased significantly over time (Fig. $\left.4 \mathrm{~A} ; \mathrm{n}=3 ;{ }^{*} \mathrm{P}<0.05 ;{ }^{*} \mathrm{P}<0.01 ;{ }^{* * *} \mathrm{P}<0.001\right)$. Additionally, as shown in Fig. 4B, MLN2238 induced the activation of BID, as indicated by the detection of t-Bid, and decreased p-BAD significantly in a dose-dependent manner $(n=3, P<0.05)$. Additionally, P53 and NOXA were up-regulated markedly in MG-63 cells $(n=3, P<0.05)$, whereas PUMA $(n=3, P>0.05)$ showed no significantly changes.

Secondly, MOMP was evaluated by detecting leaked proteins from the mitochondria to cytosol. Cells were cultured with MLN2238 for 12h, 18h or 24h and then processed to obtain the cytosolic (Cyto) and mitochondrial (Mito) fractions. The extracts were then analysed by Western blotting to detect the cytochrome c (Cytc), Smac and OMI which are released from the mitochondria to the cytosol after MOMP. As shown in Fig. 5A, MLN2238 caused a remarkable decrease in Cytc, Smac and OMI in the mitochondria, with concurrent accumulation in the cytosol over time $(n=3, P<0.05)$, indicating the leakage of the proteins from the mitochondria to the cytosol. Moreover, in the cytosolic fractions MLN2238 decreased the levels of X-linked inhibitor of apoptosis protein (XIAP) notably in a time dependent manner (Fig. 5; n=3, P< $0.05)$. PARP was further studied in whole cell lysates treated as above. As shown in Fig. 5B, the cleaved form of PARP exhibited a trend nearly identical to that of the leaked proteins above, except at $12 \mathrm{~h}(\mathrm{n}=3, \mathrm{P}<0.05)$. In summary, MLN2238 triggered MOMP and subsequently induced the release of pro-apoptotic proteins. 


\section{Cellular Physiology Cell Physiol Biochem 2017;41:451-465

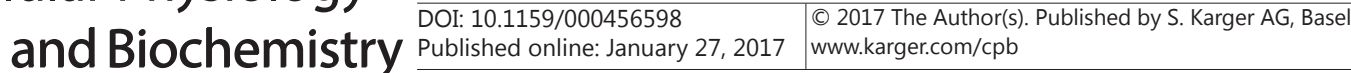

Liu et al.: Proteasome Inhibition in Osteosarcoma Therapy

MLN2238 treatment inhibits the cellular invasion ability of OS cells

To determine the effects of MLN2238 on cell invasion in OS, we performed cell invasion assays using MG-63 and Saos-2 cells. As shown in Fig. 6A, after 24h of treatment with MLN2238 at the indicated doses, invaded cells were reduced notably in a dose-dependent manner in both cell lines compared with the number of cells in the control group $\left(\mathrm{n}=3 ;{ }^{* *} \mathrm{P}<\right.$ 0.01 ; ${ }^{* * *} \mathrm{P}<0.001$ ). We also assessed the matrix metalloproteinases-MMP-2/9, which are presumed to be particularly important for tumor invasion [19]. As illustrated in Fig. 6B, MLN2238 treatment significantly reduced both the expression levels of MMP-2/9 in the cell lysates and secretion quantities in the culture medium $(n=3, P<0.05)$. Taken together, these results suggest that MLN2238 remarkably attenuates the invasion ability of OS cells in vitro.

\section{Discussion}

Protein metabolism plays a crucial role in the maintenance of cell functions. Cellular processes, including cell growth, differentiation, function and death, are normally controlled by regulatory proteins. The orderly degradation of proteins is critical for cellular processes, including which, when and where proteins are degraded [20]. Proteasomes are the principal apparatus for intracellular protein degradation. Malignant cells are characterized either by aberrant cellular proliferation or resistance to apoptosis. For viability, tumour cells with a rapid proliferation rate may require more proteasomes to remove damaged or misfolded proteins, the accumulation of which might induce apoptosis $[3,6]$. The inhibition of proteasome activity may reverse or disturb the already abnormal regulatory pathways that contribute significantly to the immortality of tumour cells $[11,12,20]$. Empirical researches have demonstrated that the inhibition of the proteasome can induce apoptosis in various tumour cells through multiple mechanisms, but these studies have not included OS. This report has demonstrated that the proteasome inhibitor MLN2238 not only inhibits the proliferation and induces the apoptosis of OS cell lines, but also attenuates the invasion ability of OS cells in vitro, which is a key reason for the high mortality associated with OS.

In this study, we showed that MLN2238 effectively inhibits the proliferation of OS cells, as assessed by the MTT assay. The growth inhibition of both cell lines induced by MLN2238 occurred in a dose- and time-dependent manner. Notably, Saos-2 cells exhibited weak sensitivity compared with MG-63 to MLN2238-induced cytotoxicity at the same dose or treatment time, discrepancy that may be ascribed to their different genetic background or living features as two different cell lines. Significantly, MLN2238 effectively inhibits the cell viability and induces apoptosis in both MG-63 and Saos- 2 cells in a favourable therapeutic index compared with normal cells (Fig. 1A). As reported, UPS plays an important role in regulating the degradation of P53 [21], which consistent with our study that proteasome inhibitor MLN2238 effectively induced the accumulation of P53 levels in MG-63 cells (Fig. 2C, Fig. 3B). As a tumour suppression factor, P53 can enhance apoptosis levels greatly in cancer therapy compared with P53 null cells [22]; However, P53 seems to be not essential for the apoptosis induced by MLN2238 in our study, as evidenced by the apparent growth inhibition of Saos-2 (P53 null) induced by MLN2238. Interestingly, at a lower dose of MLN2238 $(0.20 \mu \mathrm{M})$ for $12 \mathrm{~h}$, both cell lines exhibited increased cell viability compared with the DMSO (vehicle) treatment. A similar study also reported that proteasome inhibitor is pro- or anti-apoptosis manner depending on the concentration utilized, i.e., a low dose abrogates apoptosis, whereas a high dose induces apoptosis [23]. Further studies of the biphasic effects of MLN2238 on apoptosis are warranted.

Cell cycle arrest was observed in both cell lines treated with MLN2238 and possibly contributed to the growth inhibition. Although most studies of the up-regulation of P53 and P21 have focused on blocking the G1-S transition, our results are consistent with several previous observations that P53 and P21 play important roles in blocking the G2/M transition $[10,24]$. P53 mediated G2/M arrest is mainly through the up-regulation of P21. P21 inhibits cell cycle progression by binding to cyclin/CDK complexes and weakens their activities. Moreover, as reported, the induction of P21 is regulated through both P53-dependent and 
P53-independent pathways, which means P53 is a major transcriptional regulator of p21 but not sole $[25,26]$. Our observation is consistent with that view that the proteasome inhibitor MLN2238 increased the expression levels of P21 in both MG-63 and Saos-2 (P53 null) cells (Fig. 2C). The G2-M transition is governed by the cyclinB1/CDK1 complex directly, and phosphorylation at threonine 14 and tyrosine 15 of CDK1 maintains the complex in an inactive form, thus blocking entry into mitosis [27]. To enter mitosis, the above sites of CDK1 must be dephosphorylated by CDC25 phosphatase to activate the cyclinB1/CDK1 complex. When DNA damage occurs, CHK1 can be activated by phosphorylating on serine 345 (S345). Then, p-CHK1 keeps CDC25 being in an inactivated state by phosphorylating it, thus blocks the G2-M transition by keeping CDK1 being in phosphorylation state indirectly; and WEE1 can phosphorylate CDK1 directly at Tyr15 to inhibit the G2-M transition [27, 28, 29]. Moreover, P53 null cells, which are lacking P53 and exhibited attenuated P21 function, are more reliant on CHK1 and WEE1 to restrain CDK1 in blocking the G2-M transition [30], consistent with our results that MLN2238 treatment caused G2/M arrest accompanied with increased expression of CHK1 and WEE1 in MG-63 cells and, more apparently in Saos-2 cells (Fig. 2C). At 12h of treatment, MG-63 and Saos-2 cells exhibited the initiation of cycle arrest in G2/M and S phases, respectively. This discrepancy in phase might be attributable to the enhanced expression of E2F1 and Rb status (Fig. 2C), both of which are key effectors regulating the transition of G1 to S. E2F1 promotes the G1-S transition, whereas Rb inhibits this activity [29]. The Rb-null status of Saos-2 cells appeared to enhance the induction of the G1-S transition by the up-regulation of E2F1 compared with MG-63 cells (Fig. 2B). The Rb levels in MG-63 cells were not significantly decreased at $12 \mathrm{~h}$ compared with the control, potentially indicating maintenance of the ability to inhibit the G1-S transition. The marked decrease in $\mathrm{Rb}$, and the accumulation of E2F1 and negative regulators of $\mathrm{G} 2 / \mathrm{M}$ over time accompanied with the arrest of both cells types in S and G2/M phases (Fig. 2C). In summary, the proteasome inhibitor MLN2238 induced MG-63 and Saos-2 cell cycle arrest in $\mathrm{S}$ and G2/M phases via increased expression of E2F1 and G2/M transition-negative keepers (CHK1, WEE1 and p-Y15-CDK1).

The deregulation of the Rb-E2F pathway by the inhibition of Rb or E2F1 overexpression, can initiate apoptosis by enhancing the activation of caspases [31]. The increased expression levels of E2F1 induced by MLN2238 in our study were apparent; moreover, as described above, E2F1 also functioned as a key keeper of the G1-S transition. In combination with the $\mathrm{S}$ phase arrest observed in this study, these results indicated that E2F1 might function both in the cell cycle regulation and induction of apoptosis by MLN2238, thus coupling cell cycle arrest and apoptosis progression consistent with a previous report [32].

APAF-1, a weakly expressed factor in the intrinsic apoptosis pathway, plays a role in apoptosis by forming the apoptosome with cytochrome c and pro-caspase9, which, is a caspase activation platform that can cleave pro-caspase9, triggering the intrinsic apoptotic pathway. APAF-1 is assumed to be a limiting factor in the apoptosis pathway [33]. In the present study, MLN2238 induced the up-regulation of APAF-1, which favoured the initiation of apoptosis. Moreover, APAF-1 can be up regulated by E2F1 too [32, 33].

We further confirmed that MLN2238 induced the apoptosis of OS cells, as assessed by apoptosis assays using Flow cytometric, and cleaved caspase 3 and PARP levels. The cleavage of caspase 3 and PARP is a signature event and indicator of apoptosis. In mammalian cells, apoptosis mainly occurs via two pathways, the extrinsic and intrinsic pathway, both of which converge to activate the apoptosis executioner caspase3 [34]. Caspase8 is a key element for the activation of both pathways; when activated, it initiates apoptosis via two mechanisms. First, activated caspase8 cleaves and activates caspase3, leading to cellular demise (the extrinsic pathway). Second, activated caspase8 cleaves Bid, a BH3-only pro-apoptotic protein in the BCL-2 family, to its truncated form t-Bid, which binds to BAX and BAK, triggering MOMP and the intrinsic apoptotic pathway. The latter includes the activation of caspase9, which then cleaves caspase3, leading to apoptosis. The intrinsic pathway is only partially activated by caspase 8 and occurs mainly through the initiation of MOMP triggered by the pro-apoptotic proteins of the BCL-2 family [35]. In the present study, MLN2238 induced the 
activation of both caspase 8 and caspase9, indicating that MLN2238 induces apoptosis in OS cells via crosstalk between the extrinsic and intrinsic pathways [34]. This conclusion was further supported in experiments using inhibitors of caspase8 and caspase9. Moreover, the apoptosis of OS cells induced by MLN2238 occurred mainly through the caspase-dependent pathway, because the pan-caspase inhibitor (Z-VAD-FMK) nearly abrogated apoptosis.

MOMP, which causes the release of pro-apoptotic proteins located in the mitochondrial intermembrane space, is considered a fundamental event in the initiation of intrinsic apoptosis. MOMP is highly regulated by the pro-apoptotic (e.g. BAX, BAK, BID, PUMA, and NOXA) and anti-apoptotic (e.g., BCL-2, BCL-xL) members of the B cell lymphoma 2 family and is triggered mainly through the activation of BAX and/or BAK because cells lacking both fail to undergo MOMP [36]. There are two pathways for the activation of BAX/BAK: the indirect activator pathway and the direct activator-derepressor pathway. In the indirect pathway, BAX and BAK are in a constitutively active state; but are limited and sequestered by anti-apoptotic proteins (e.g., BCL-2); pro-apoptotic proteins (e.g., BID, PUMA and BAD) can release BAX and $\mathrm{BAK}$ by inhibiting or binding to the BCL-2 protein. In the direct activator-derepressor pathway, BAX and BAK can be activated directly by the interaction of pro-apoptotic proteins (e.g., t-Bid and PUMA); anti-apoptotic proteins prevent their activation either by directly inhibiting or sequestering the pro-apoptotic proteins. In addition, pro-apoptotic proteins that cannot directly activate BAX and BAK can neutralize anti-apoptotic proteins to facilitate the activation of BAX and BAK [37]. The accumulation of BAX can also overcome the survival effect of BCL-2 [38]. BCL-2, a mainly anti-apoptotic protein, is up-regulated in various cancers, hindering cell death or promoting drug resistance in malignant cells [39]. Furthermore, the overexpression of BCL-2 can prevent the initiation of MOMP under cellular stress [37, 40]. As shown in this study, MLN2238 significantly decreased the levels of BCL-2, and elevated the pro-apoptotic 'effector' molecule BAX. The relative expression of these two key antagonistic factors to MOMP, as assessed by the BAX/BCL-2 ratio, increased significantly over time after MLN2238 treatment, and the balance was shifted in the pro-apoptosis direction, contributing to MOMP and mitochondria-mediated apoptosis. NOXA and PUMA are two modulators of apoptosis regulated by P53 [41, 42], and P53 and NOXA, but not PUMA, were increased notably. T-BID, a truncated form of Bid cleaved by activated caspase-8 (Fig. 3A) that is thought to be a key regulator of MOMP by directly activating of BAX and BAK [43], was also detected in the present study. BAD is a pro-apoptotic protein of the BCL-2 family that promotes apoptosis by liberating BAX from BCL-2/BCL-xL, and phosphorylation of BAD can prevent its pro-apoptotic function $[37,44]$. MLN2238 treatment decreased p-BAD, suggesting the enhancement of BAD. Taken together, these results suggest that the effects of MLN2238 on MOMP involve not only the effector factors-BAX and BCL-2, but also assistant factors in OS cells even in cells deficient in P53 (Saos-2).

The shifted balance between pro- and anti-apoptotic proteins ultimately leads to MOMP upon treatment with MLN2238, as indicated by the detection of the release of Cytc, Smac and OMI from mitochondria to the cytoplasm. The accumulation of Cytc (Fig. 5A) in the cytoplasm accompanied by pro-caspase 9 (Fig. 3A) and APAF-1 (Fig. 2C) forms apoptosome, which triggers the intrinsic apoptotic pathway [35]. XIAP, an inhibitor of caspase3/7/9, suppresses apoptosis at the final juncture by inhibiting the activity of cleaved caspases through direct binding. We observed a decrease in XIAP levels in the cytosolic fractions after MLN2238 treatment, similar to a previous finding that the proteasome inhibitor rapidly diminished cytoplasmic XIAP in tumour cells and accelerated apoptosis [45]. Moreover, we further detected the leakage of Smac and OMI from the mitochondria to the cytoplasm upon MLN2238 treatment. Smac and OMI, which are considered secondary mitochondria-derived activators of caspase, bind to IAPs directly and prevent their interactions with caspases, thus counteracting their inhibition effects on caspases, particularly for XIAP [46]. Smac and OMI are both normally located in the intermembrane space of the mitochondria and are released simultaneously with cytochrome c from the mitochondria during apoptosis [35]. Considerable accumulation of Cytc, Smac and OMI in the cytoplasm was observed as early as $12 \mathrm{~h}$ in the present study, but did not lead to induction of apoptosis as shown by 
the MTT assay and PARP time-course analysis. At $12 \mathrm{~h}$ of treatment, the viability of both cell lines treated with MLN2238 was nearly as high as that of the control groups, and cleaved PARP was barely detectable, indicating few apoptotic events. These observations might be attributable to the antagonism effects of XIAP on caspases; the levels of XIAP at $12 \mathrm{~h}$ were still sufficient to combat the MOMP-induced caspase cascade effect. Over time, the decreased expression of XIAP and enforced MOMP effects ultimately led to cell apoptosis. Moreover, the rapid triggering of MOMP and sustained accumulation of pro-apoptotic proteins (e.g. P53/ $\mathrm{BAX} /$ Cyto-c/Smac) was confirmed to be the initiation event rather than the result of cell death.

Active metastasis contributes to the poor survival and high mortality of OS. In the present study, we determined that MLN2238 suppresses the invasion ability of OS cells in vitro effectively, as demonstrated by Transwell assays. To reveal the potential molecular mechanism, we explored matrix metalloproteinase factors, which regulate tumour metastasis, particularly MMP2 and MMP9 [47, 48]. MLN2238 significantly reduced the expression levels of MMP2/9 in total cell lysates, indicating decreased endogenous expression upon MLN2238 treatment. As two exocrine proteins, MMP2 and MMP9 exert their invasion function extracellularly, thus we further explored their levels in the culture medium. Consistent with previous reports $[49,50]$, the secretion levels of MMP2/9 decreased dramatically upon MLN2238 treatment, particularly for MMP2, which plays an important role in tumour angiogenesis and metastasis [48]. Both endogenous and exocrine levels of MMP2/9 declined after MLN2238 treatment, potentially contributing to the attenuated invasion ability of the OS cells. To confirm the efficacy of MLN2238 in suppressing the distal metastasis ability of OS, in vivo metastasis assays are needed. We were unable to perform these assays due to the unavailable experimental conditions, which is a limitation of our study.

In summary, we suggest that the antitumour effects of the proteasome inhibitor MLN2238 in OS cells, involve cell cycle arrest, MOMP, mitochondrial-dependent and -independent apoptosis and attenuated invasion ability in both MG-63 and Saos-2 cells. Our study highlights that, as an anticancer agent, the proteasome inhibitor MLN2238 functioned well in OS cells in vitro, and the proteasome may be a novel biochemical target for OS treatment. Moreover, MLN9708 is orally bioavailable and is now in phase I and I/II clinical development making it more appropriate for further in vivo and clinical research for OS treatment.

\section{Acknowledgments}

The work was supported by National Natural Science Foundation of China (No. 81171692).

\section{Disclosure Statement}

The authors declare no conflict of interest.

\section{References}

1 Adams J: The proteasome: A suitable antineoplastic target. Nat Rev Cancer 2004;4:349-360.

2 Bhattacharyya S, Yu H, Mim C, Matouschek A: Regulated protein turnover: snapshots of the proteasome in action. Nat Rev Mol Cell Biol 2014;15:122-133.

Lee EC, Fitzgerald M, Bannerman B, Donelan J, Bano K, Terkelsen J, Bradley DP, Subakan O, Silva MD, Liu R, Pickard M, Li Z, Tayber O, Li P, Hales P, Carsillo M, Neppalli VT, Berger AJ, Kupperman E, Manfredi M, Bolen JB, Van Ness B, Janz S: Antitumor activity of the investigational proteasome inhibitor MLN9708 in mouse models of B-cell and plasma cell malignancies. Clin Cancer Res 2011;17:7313-7323. 


\section{Cellular Physiology Cell Physiol Biochem 2017;41:451-465 \begin{tabular}{l|l} 
DOI: 10.1159/000456598 & $\begin{array}{l}\text { O 2017 The Author(s). Published by S. Karger AG, Basel } \\
\text { www.karger.com/cpb }\end{array}$ \\
\hline
\end{tabular}}

Liu et al.: Proteasome Inhibition in Osteosarcoma Therapy

4 Masdehors P, Omura S, Merle-Béral H, Mentz F, Cosset JM, Dumont J, Magdelénat H, Delic J: Increased sensitivity of CLL-derived lymphocytes to apoptotic death activation by the proteasome-specific inhibitor lactacystin. Br J Haematol 1999;105:752-757.

-5 Soligo D, Servida F, Delia D, Fontanella E, Lamorte G, Caneva L, Fumiatti R, Lambertenghi Deliliers G: The apoptogenic response of human myeloid leukaemia cell lines and of normal and malignant haematopoietic progenitor cells to the proteasome inhibitor PSI. Br J Haematol 2001;113:126-135.

-6 Guzman ML, Swiderski CF, Howard DS, Grimes BA, Rossi RM, Szilvassy SJ, Jordan CT: Preferential induction of apoptosis for primary human leukemic stem cells. Proc Natl Acad Sci USA 2002;99:16220-16225.

7 Chauhan D, Tian Z, Zhou B, Kuhn D, Orlowski R, Raje N, Richardson P, Anderson KC: In vitro and in vivo selective antitumor activity of a novel orally bioavailable proteasome inhibitor MLN9708 against multiple myeloma cells. Clin Cancer Res 2011;17:5311-5321.

8 Kupperman E, Lee EC, Cao Y, Bannerman B, Fitzgerald M, Berger A, Yu J, Yang Y, Hales P, Bruzzese F, Liu J, Blank J, Garcia K, Tsu C, Dick L, Fleming P, Yu L, Manfredi M, Rolfe M, Bolen J: Evaluation of the proteasome inhibitor MLN9708 in preclinical models of human cancer. Cancer Res 2010;70:1970-1980.

-9 Drexler HC, Risau W, Konerding MA: Inhibition of proteasome function induces programmed cell death in proliferating endothelial cells. FASEB J 2000;14:65-77.

10 Adams J, Palombella VJ, Sausville EA, Johnson J, Destree A, Lazarus DD, Maas J, Pien CS, Prakash S, Elliott PJ: Proteasome inhibitors: a novel class of potent and effective antitumor agents. Cancer Res 1999;59:26152622.

11 Orlowski RZ, Kuhn DJ: Proteasome inhibitors in cancer therapy: lessons from the first decade. Clin Cancer Res 2008;14:1649-1657.

12 Nalepa G, Rolfe M, Harper JW: Drug discovery in the ubiquitin-proteasome system. Nat Rev Drug Discov 2006;5:596-613.

13 Tang N, Song W X, Luo J, Haydon R C, He T C: Osteosarcoma development and stem cell differentiation. Clin Orthop Relat Res 2008;466:2114-2130.

14 Li R, Zhang W, Cui J, Shui W, Yin L, Wang Y, Zhang H, Wang N, Wu N, Nan G, Chen X, Wen S, Deng F, Zhang H, Zhou G, Liao Z, Zhang J, Zhang Q, Yan Z, Liu W, Zhang Z, Ye J, Deng Y, Luu HH, Haydon RC, He TC, Deng ZL: Targeting BMP9-promoted human osteosarcoma growth by inactivation of notch signaling. Curr Cancer Drug Targets 2014;14:274-285.

15 Wang Y, Yin RF, Teng JS: Wogonoside induces cell cycle arrest and mitochondrial mediated apoptosis by modulation of Bcl-2 and Bax in osteosarcoma cancer cells. Int J Clin Exp Pathol 2015;8:63-72.

16 Dick LR, Fleming PE: Building on bortezomib: second-generation proteasome inhibitors as anti-cancer therapy. Drug Discov Today 2010;15:243-249.

17 Liu X, He Y, Li F, Huang Q, Kato TA, Hall RP, Li CY: Caspase-3 promotes genetic instability and carcinogenesis. Mol Cell 2015;58:284-296.

18 Wu HM, Jiang ZF, Ding PS, Shao LJ, Liu RY: Hypoxia-induced autophagy mediates cisplatin resistance in lung cancer cells. Sci Rep 2015;5:12291.

19 Clark IM, Swingler TE, Sampieri CL, Edwards DR: The regulation of matrix metalloproteinases and their inhibitors. Int J Biochem Cell Biol 2008;40:1362-1378.

20 Jung T, Catalgol B, Grune T: The proteasomal system. Mol Aspects Med 2009;30:191-296.

21 Yang L, Zhou B, Li X, Lu Z, Li W, Huo X, Miao Z: RNF125 is a ubiquitin-protein ligase that promotes p53 degradation. Cell Physiol Biochem 2015;35:237-245.

22 MacLaren AP, Chapman RS, Wyllie AH, Watson CJ: p53-dependent apoptosis induced by proteasome inhibition in mammary epithelial cells. Cell Death Differ 2001;8:210-218.

23 Lin KI, Baraban JM, Ratan RR: Inhibition versus induction of apoptosis by proteasome inhibitors depends on concentration. Cell Death Differ 1998;5:577-583.

24 Ling YH, Liebes L, Ng B, Buckley M, Elliott PJ, Adams J, Jiang JD, Muggia FM, Perez-Soler R: PS-341, a novel proteasome inhibitor, induces Bcl-2 phosphorylation and cleavage in association with G2-M phase arrest and apoptosis. Mol Cancer Ther 2002;1:841-849.

25 Bunz F, Dutriaux A, Lengauer C, Waldman T, Zhou S, Brown JP, Sedivy JM, Kinzler KW, Vogelstein B: Requirement for p53 and p21 to sustain G2 arrest after DNA damage. Science 1998;282:1497-1501.

26 Raffoul JJ, Wang Y, Kucuk O, Forman JD, Sarkar FH, Hillman GG: Genistein inhibits radiation-induced activation of NF-kappaB in prostate cancer cells promoting apoptosis and G2/M cell cycle arrest. BMC Cancer 2006;6:107. 


\section{Cellular Physiology Cell Physiol Biochem 2017;41:451-465

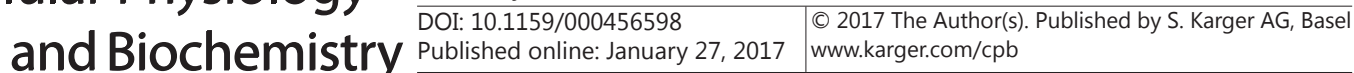

Liu et al.: Proteasome Inhibition in Osteosarcoma Therapy

27 Thompson R, Eastman A: The cancer therapeutic potential of Chk1 inhibitors: how mechanistic studies impact on clinical trial design. Br J Clin Pharmacol 2013;76:358-369.

28 Lindqvist A, Rodriguez-Bravo V, Medema RH: The decision to enter mitosis: feedback and redundancy in the mitotic entry network. J Cell Biol 2009;185:193-202.

29 Xu W, McArthur G: Cell Cycle Regulation and Melanoma. Curr Oncol Rep 2016;18:34.

- 30 Aarts M, Sharpe R, Garcia-Murillas I, Gevensleben H, Hurd MS, Shumway SD, Toniatti C, Ashworth A, Turner NC: Forced mitotic entry of S-phase cells as a therapeutic strategy induced by inhibition of WEE1. Cancer Discov 2012;2:524-539.

- 31 Cam H, Dynlacht BD: Emerging roles for E2F: beyond the G1/S transition and DNA replication. Cancer Cell 2003;3:311-316.

32 Nahle Z, Polakoff J, Davuluri RV, McCurrach ME, Jacobson MD, Narita M, Zhang MQ, Lazebnik Y, Bar-Sagi D, Lowe SW: Direct coupling of the cell cycle and cell death machinery by E2F. Nat Cell Biol 2002;4:859-864.

-33 Moroni MC, Hickman ES, Lazzerini Denchi E, Caprara G, Colli E, Cecconi F, Müller H, Helin K: Apaf-1 is a transcriptional target for E2F and p53. Nat Cell Biol 2001;3:552-558.

34 Danial NN, Korsmeyer SJ: Cell death: critical control points. Cell 2004;116:205-219.

-35 Tait SW, Green DR: Mitochondria and cell death: Outer membrane permeabilization and beyond. Nat Rev Mol Cell Biol 2010;11:621-632.

- 36 Wei MC, Zong WX, Cheng EH, Lindsten T, Panoutsakopoulou V, Ross AJ, Roth KA, MacGregor GR, Thompson CB, Korsmeyer SJ: Proapoptotic BAX and BAK: a requisite gateway to mitochondrial dysfunction and death. Science 2001;292:727-730.

- 37 Delbridge AR, Strasser A: The BCL-2 protein family, BH3-mimetics and cancer therapy. Cell Death Differ 2015;22:1071-1080.

- 38 Li B, Dou QP: Bax degradation by the ubiquitin/proteasome-dependent pathway: involvement in tumor survival and progression. Proc Natl Acad Sci USA 2000;97:3850-3855.

39 Adams JM, Cory S: The Bcl-2apoptotic switch in cancer development and therapy. Oncogene 2007;26:1324-1337.

40 Green DR, Kroemer G: The pathophysiology of mitochondrial cell death. Science 2004;305:626-629.

-41 Oda E, Ohki R, Murasawa H, Nemoto J, Shibue T, Yamashita T, Tokino T, Taniguchi T, Tanaka N: Noxa, a BH3-only member of the Bcl-2 family and candidate mediator of p53-induced apoptosis. Science 2000;288:1053-1058.

42 Yu J, Zhang L, Hwang PM, Kinzler KW, Vogelstein B: PUMA induces the rapid apoptosis of colorectal cancer cells. Mol Cell 2001;7:673-682.

43 Lovell JF, Billen LP, Bindner S, Shamas-Din A, Fradin C, Leber B, Andrews DW: Membrane binding by tBid initiates an ordered series of events culminating in membrane permeabilization by Bax. Cell 2008;135:1074-1084.

-44 Zha J, Harada H, Yang E, Jockel J, Korsmeyer SJ: Serine phosphorylation of death agonist BAD in response to survival factor results in binding to 14-3-3 not BCL-X(L). Cell 1996;87:619-628.

45 Cater MA, Haupt Y: Clioquinol induces cytoplasmic clearance of the X-linked inhibitor of apoptosis protein (XIAP): therapeutic indication for prostate cancer. Biochem J 2011;436:481-491.

-46 Du C, Fang M, Li Y, Li L, Wang X: Smac, a mitochondrial protein that promotes cytochrome c-dependent caspase activation by eliminating IAP inhibition. Cell 2000;102:33-42.

47 Kim Y, Kang H, Jang SW, Ko J: Celastrol inhibits breast cancer cell invasion via suppression of NF-kBmediated matrix metalloproteinase-9 expression. Cell Physiol Biochem 2011;28:175-184.

48 Liu WH, Chen YJ, Chien JH, Chang LS: Amsacrine suppresses matrix metalloproteinase-2 (MMP-2)/MMP-9 expression in human leukemia cells. J Cell Physiol 2014;229:588-598.

49 Chou WM, Liu WH, Chen KC, Chang LS: Structure-function studies on inhibitory activity of Bungarus multicinctus protease inhibitor-like protein on matrix metalloprotease-2, and invasion and migration of human neuroblastoma SK-N-SH cells. Toxicon 2010;55:353-360.

-50 Liu Y, Cao W, Zhang B, Liu YQ, Wang ZY, Wu YP, Yu XJ, Zhang XD, Ming PH, Zhou GB, Huang L: The natural compound magnolol inhibits invasion and exhibits potential in human breast cancer therapy. Sci Rep 2013;3:3098. 